\title{
Tibia functionality and Division II female and male collegiate athletes from multiple sports
}

\author{
Vanessa R Yingling ${ }^{\text {Corresp.. }}{ }^{1}$ ， Benjamin Ferrari-Church ${ }^{1}$ ， Ariana Strickland \\ ${ }^{1}$ Department of Kinesiology, California State University, East Bay, Hayward, California, United States \\ Corresponding Author: Vanessa R Yingling \\ Email address: vanessa.yingling@csueastbay.edu
}

Background. Bone strength is developed through a combination of the size and shape (architecture) of a bone as well as the bone's material properties; and therefore, no one outcome variable can measure a positive or negative adaptation in bone. Skeletal robusticity (total area/ bone length) a measure of bones external size varies within the population and is independent of body size, but robusticity has been associated with bone strength. Athletes may have similar variability in robusticity values as the general population and thus have a wide range of bone strengths based on the robustness of their bones. Therefore, the purpose of this study was to determine if an athlete's bone strength and cortical area relative to body size was dependent on robusticity. The second aim was to determine if anthropometry or muscle function measurements were associated with bone robusticity. Methods. Bone variables contributing to bone strength were measured in collegiate athletes and a reference group using peripheral quantitative computed tomography (pQCT) at the $50 \%$ tibial site. Bone functionality was assessed by plotting bone strength and cortical area vs body size (body weight $x$ tibial length) and robustness (total area/length) vs body size. Bone strength was measured using the polar strengthstrain index (SSIp). Based on the residuals from the regression, an athlete's individual functionality was determined, and two groups were formed "weaker for size" (WS) and "stronger for size" (SS). Grip strength, leg extensor strength and lower body power were also measured. Results. Division II athletes exhibited a natural variation in (SSIp) relative to robusticity consistent with previous studies. Bone strength (SSIp) was dependent on the robusticity of the tibia. The bone traits that comprise bone strength (SSIp) were significantly different between the SS and WS groups, yet there were minimal differences in the anthropometric data and muscle function measures between groups. A lower percentage of athletes from ball sports were "weaker for size" (WS group) and a higher percentage of swimmers were in the WS group. Discussion. A range of strength values based on robusticity occurs in athletes similar to general populations. Bones with lower robusticity (slender) were constructed with less bone tissue and had less strength. The 
athletes with slender bones were from all sports including track and field and ball sports but the majority were swimmers. Conclusions. Athletes, even after optimal training for their sport, may have weaker bones based on robusticity. Slender bones may therefore be at a higher risk for fracture under extreme loading events but also yield benefits to some athletes (swimmers) due to their lower bone mass. 
1

2

3

4

5

6

7 Department of Kinesiology, California State University, East Bay

8 Vanessa.yingling@csueastbay.edu

9 California State University, East Bay

10 Department of Kinesiology

1125800 Carlos Bee Boulevard

12 Hayward, CA 94542

13 Office: $510-885-3064$

14 Fax: 510-885-2423

15

16

Running Title: Tibia functionality and Athletes 
Abstract word count: 423

Background. Bone strength is developed through a combination of the size and shape

(architecture) of a bone as well as the bone's material properties; and therefore, no one outcome variable can measure a positive or negative adaptation in bone. Skeletal robusticity (total area/ bone length) a measure of bones external size varies within the population and is independent of body size, but robusticity has been associated with bone strength. Athletes may have similar variability in robusticity values as the general population and thus have a wide range of bone strengths based on the robustness of their bones. Therefore, the purpose of this study was to determine if an athlete's bone strength and cortical area relative to body size was dependent on robusticity. The second aim was to determine if anthropometry or muscle function measurements were associated with bone robusticity. Methods. Bone variables contributing to bone strength were measured in collegiate athletes and a reference group using peripheral quantitative computed tomography (pQCT) at the 50\% tibial site. Bone functionality was assessed by plotting bone strength and cortical area vs body size (body weight $\mathrm{x}$ tibial length) and robustness (total area/length) vs body size. Bone strength was measured using the polar strength-strain index (SSIp). Based on the residuals from the regression, an athlete's individual functionality was determined, and two groups were formed "weaker for size" (WS) and "stronger for size" (SS). Grip strength, leg extensor strength and lower body power were also measured. Results. Division II athletes exhibited a natural variation in (SSIp) relative to robusticity consistent with previous studies. Bone strength (SSIp) was dependent on the robusticity of the tibia. The bone traits that comprise bone strength (SSIp) were significantly different between the

42 SS and WS groups, yet there were minimal differences in the anthropometric data and muscle 
43 function measures between groups. A lower percentage of athletes from ball sports were

44 "weaker for size" (WS group) and a higher percentage of swimmers were in the WS group.

45 Discussion. A range of strength values based on robusticity occurs in athletes similar to general

46 populations. Bones with lower robusticity (slender) were constructed with less bone tissue and

47 had less strength. The athletes with slender bones were from all sports including track and field

48 and ball sports but the majority were swimmers. Conclusions. Athletes, even after optimal

49 training for their sport, may have weaker bones based on robusticity. Slender bones may

50 therefore be at a higher risk for fracture under extreme loading events but also yield benefits to

51 some athletes (swimmers) due to their lower bone mass. 
56

57 Bones must be sufficiently strong to support loading from daily activities and avoid injury.

Introduction

Adequate bone strength during development may not only prevent injury in the short-term but may also decrease fracture incidence later in life (Heaney et al., 2000). However, bone strength is a complex concept and is determined by the size and shape (architecture) of a bone as well as the bone's material properties_(Van der Meulen, Jepsen \& Mikić, 2001). Therefore, one variable cannot be used to determine the bone strength or the potential for injury; multiple outcome measures are necessary to effectively monitor bones' response to exercise.

Robusticity, a measure of external bone size, is one of many genetic and anatomical factors that limit or permit bone adaptation and thus bone strength in the skeletal system (Pandey et al., 2009). Skeletal robusticity reflects the biological relationship between periosteal expansion relative to longitudinal growth (Pandey et al., 2009) and is a heritable trait established by 2 years of age. Robusticity values vary within the population but are independent of body size. The range of robusticity values (slender (low) to robust (high)) affect the ability of bone to adjust the tissue modulus or architecture to develop a sufficiently strong bone to withstand daily activities. Slender bones (low robusticity) are constructed with significantly less bone mass than more robust bones (Jepsen et al., 2011) resulting in relatively weaker bones that may be at greater risk for fracture, specifically stress fractures (Crossley et al., 1999; Jones, 2002; Taes et al., 2010; Jepsen et al., 2013). Individuals have different bone strength dependent on the robusticity of their bones. Two people with similar body sizes can have widely varied robusticity and thus varied bone strength (Jepsen et al., 2011). Relatively weak bones for body size may not be a problem during activities of daily living but may be detrimental under extreme loading 
conditions such as those experienced by athletes during training and competition. Therefore, it is important to determine if athletes have a similar variability in robusticity values as the general population and if their bone strength is affected by robusticity in similar ways that have been found in healthy populations.

Higher bone density and larger bone size (moment of inertia) have been identified in athletes compared to sedentary controls illustrating the positive effect of physical activity on bone (Haapasalo et al., 2000; Greene et al., 2012). In fact, baseball and racquet sport athletes have long term bone strength benefits, especially those athletes starting their sport during adolescence (Kontulainen et al., 2003; Warden \& Roosa, 2014; Jackowski et al., 2014). Yet, a relatively large percentage of athletes develop stress fractures accounting for $0.7 \%$ to $20 \%$ of all sports medicine clinic injuries - an indication of either relatively weak bones or excessive loading (Fredericson et al., 2006). Athletes cannot be grouped as a homogenous population, both intrinsic (genetic and biological) and extrinsic (environment, nutrition, training) factors affect both performance and the incidence of injury. Risk factors for injury include training errors, training gear (shoes and orthotics), anatomical and genetic risk factors including body size, tibial width and muscle strength.

Therefore, athletes may also have a large variation in robusticity and thus bone strength values relative to body size. The purpose of this study was to determine if an athlete's bone strength and cortical area relative to body size were dependent on robusticity and if anthropometric or muscle function differed between athletes of different robusticity values. It was hypothesized that there would be a difference in bone strength and cortical area dependent on robusticity in 
102 Division II collegiate athletes but no differences in anthropometry or muscle function would be 103 found.

104

105 Materials \& Methods:

106

107 Participants:

108

A total of 105 university students participated in this study including 86 student athletes and 19 non-student athletes making up the reference group. Fifty-four female athletes $(24.1 \%$ African American/Black, 11.1\% Latina, 31.5\% White, 13.0\% Asian, 20.4\% Mixed Race or Unknown), 37 male athletes (21.6\% African American/Black, 27.0\% Latino, 24.3\% White, 2.7\% Asian, 2.7\% Pacific Islander, 21.6\% Mixed Race or Unknown) and 19 referents (8 females, 11 males) (5\% African American/Black, 16\% Latino, 10\% White, 32\% Asian, 5\% Pacific Islander, 32\% Mixed Race or Unknown) were used in the analysis. Participants' average age was $20.7 \pm 2.2$ (18-29) years. Female athletes were members of the track and cross country (Track, CC), volleyball, soccer and swim teams. Male athletes were members of the track and cross country (Track, CC), soccer and basketball teams. All participants provided written informed consent and all study procedures were approved by the Institutional Review Board of California State University, East Bay (CSUEB-IRB-2014-004-F). A general health and demographic survey was completed. Participants were excluded if they had a history of any diseases that might influence bone mineral density (endocrine diseases, gastrointestinal disorders, and eating disorders), 123 smoked or were pregnant. 
125

Anthropometry and Muscle Strength:

126 Body weight and body fat percentage were measured using the BOD POD (COSMED USA,

127 Concord, CA). Height was measured in meters using a stadiometer. Maximal grip strength was

128 tested in a standing posture with arms at sides using a hand dynamometer (BIOPAC Systems Inc,

129 Goleta, CA). Three trials were completed with a 30 second rest between each trial for both right

130 and left hands. A relative measure of the combined force relative to body weight was then

131 calculated. Leg extensor strength was measured using the one repetition maximum test (1 RM)

132 on a bilateral leg-press machine (Hammer Strength-Life Fitness, Rosemont, IL). Testing did not

133 take place after practice or a weight training session or on the same day as the vertical jump test.

134 To perform the $1 \mathrm{RM}$, participants were instructed to place feet flat on the platform, hips width

135 apart, toes rotated slightly outward with knees flexed to 70 degrees and then extend knees to 170

136 degrees. After a warm up and a familiarization period, the load was set to $90-95 \%$ of their

137 predicted 1 RM. Following each successful lift, the weight was increased by $\sim 5 \%$ until the

138 participant failed to lift the load through the entire range of motion. Approximately 3-5 min. rest periods were allowed between each trial. A repetition was considered valid when the participant used proper form and completed the lift through the full range of motion in a controlled manner without assistance. The 1RM represents the highest weight that can be lifted one time using proper technique through the full range of motion. A vertical jump test was used to estimate lower body power. Jump height was quantified using a Vertec ${ }^{\mathrm{TM}}$ (JUMPUSA.com, Sunnyvale, CA), a common tool for measuring vertical jump ability. The Vertec ${ }^{\mathrm{TM}}$ is a steel structure with horizontal vanes which are rotated out of the way by the hand to indicate the height reached. A standing reach value was measured with the participants arm overhead and both feet flat on the ground. Participants then completed three counter movement vertical jumps (CMVJ). The 
148 CMVJ maximal height was calculated as the difference between the height jumped and the

149 standing reach height. The maximal jump height of three trials was used to calculate peak power 150 and relative peak power.

151

152 Sayers CMJ Peak Power Equation (Sayers et al., 1999)

153 Peak Power $(W)=[51.9 *$ CMJ height $(\mathrm{cm})]+[48.9 *$ Body mass $(\mathrm{kg})]-2007$

154 Relative Peak Power Equation

155 Relative Peak Power $\left(W^{*} k g^{-1}\right)=$ Peak Power $(W) /$ Body Weight $(\mathrm{kg})$

156

157

Bone Mass, Structure and Distribution:

158

159

Bone images were obtained for the dominant tibia (Korhonen et al., 2012) using peripheral

160 quantitative computed tomography (pQCT) (XCT 2000 Stratec Medizintechnik, Pforzheim, Germany). Tibia dominance was determined by asking participants, "Which leg is your dominant leg?" if they responded inconclusively a follow up question of, "Which hand do you write with?" was asked. Tibia length was measured as the distance between the medial malleolus and medial epicondyle with the knee flexed to 90 degrees. The length measurement was repeated twice, and the average was taken.

For all participants, a scout scan was performed to locate the distal end of the tibia to determine the $25 \%$ and $50 \%$ sites of the tibia length, after which the two sites were scanned. The voxel size was set to $0.5 \mathrm{~mm}$, slice thickness was $2 \mathrm{~mm}$ and the scanning speed was $30 \mathrm{~mm} / \mathrm{s}$. The $25 \%$ site was predominately cortical diaphyseal bone. At the $50 \%$ site both cortical bone and muscle area 
170 were measured. Slice images were analyzed using manufacturer's software (version 6.20).

171 Regions of Interest (ROI) were identified using auto find and minimize functions of the 2000L

172 software package, manual corrections were made using visual check as necessary. Contour

173 mode 1 with a threshold of $710 \mathrm{mg} / \mathrm{cm}^{3}$ defined cortical bone and to determine the strength-

174 strain index (SSIp) a contour mode of 1 and a threshold of $480 \mathrm{~mm} / \mathrm{cm}^{3}$ was used. At both the

$17525 \%$ and 50\%-tibia sites, cortical bone mineral density cBMD (CRT_DEN, mg/cm ${ }^{3}$ ), total area

176 T.Ar (TOT_A, $\left.\mathrm{mm}^{2}\right)$, cortical area Ct.Ar $\left(\mathrm{CRT} \_\mathrm{A}, \mathrm{mm}^{2}\right)$, periosteal perimeter, Ps.Pm (PERI_C,

$177 \mathrm{~mm})$, endocortical perimeter, Ec.Pm (ENDO_C, mm), cortical thickness Ct.Wi (CRT_THK_C,

$178 \mathrm{~mm}$ ) and polar moment of inertia, J (IP_CM_W, $\mathrm{mm}^{4}$ ) and strength-strain index SSIp

179 (RP_CM_W, $\left.\mathrm{mm}^{3}\right)$ were measured. Muscle cross-sectional area $\left(\mathrm{mm}^{2}\right)$ was determined from the

$18050 \%$-tibia site. Robusticity was determined at the $25 \%$ and $50 \%$-tibia sites as the total area

181 divided by bone length.

$182 \mathrm{SSIp}=\left(\mathrm{MI} / \mathrm{D}_{\max }\right) *(\mathrm{CD} / \mathrm{ND})($ Cointry et al., 2014)

183 MI: Moment of Inertia

$184 \mathrm{D}_{\max }=$ maximum distance of a voxel from center of gravity

$185 \mathrm{CD}=$ measured cortical density $\left(\mathrm{mg} / \mathrm{cm}^{3}\right)$ mineral per unit of cortical bone volume

$186 \mathrm{ND}=$ normal physiological density $\left(1200 \mathrm{mg} / \mathrm{cm}^{3}\right)$

188 All scans were acquired and analyzed by 1 of 2 technicians holding Limited Permit X-Ray

189 Technician certifications from the California Department of Public Health. The short term in

190 vivo precision (CV \%) in our laboratory for all the variables used has been assessed and

191 estimated between $0.22 \%$ and $1.7 \%$. All scans were checked for movement artifacts at the time

192 of the initial scan by the technician. Manufacturer supplied hydroxyapatite phantoms for pQCT

193 were scanned daily prior to data collection. 
194 Robusticity and Bone Strength relative to Body Size

195

196

197

198

199

200

201

202

203

204

205

206

207

208

209

210

211

212

213

214

215

216

Whole bone strength was estimated from pQCT images using the Strength-Strain Index (SSIp).

Body size was calculated as the product of body weight (BW) and tibial bone length (Le)

$\left(\mathrm{BW}^{*} \mathrm{Le}\right)$. Robusticity was calculated as the total area of the bone divided by the bone length at the $50 \%$ site (Figure 1A). The hypothesis that variation in bone strength varies by robusticity after adjusting for body size in a population of collegiate athletes was tested. Traditionally bone mechanical function is reported relative to a measure of body size. Bone functionality was assessed for males and females separately by plotting bone strength vs body size (body weight $\mathrm{x}$ tibia length: BW*Le) (Figure 1C). For males and females separately, robusticity was also regressed against body size $\left(\mathrm{BW}^{*} \mathrm{Le}\right)$ (Figure $\left.1 \mathrm{~B}\right)$. The residuals from the regressions represent the variation within SSIp and robusticity that is not explained by body size (BW * Le). Using the residuals, SSIp was then regressed against robusticity by partial regression analysis. A slope greater than zero for the partial regression indicates that bone strength is dependent on robusticity (Figure 1D). A partial linear regression between cortical area (Ct.Ar) and robusticity accounting for body size $\left(\mathrm{BW}^{*} \mathrm{Le}\right)$ was then completed to determine any dependence of cortical area on robusticity. A slope greater than zero for the partial regression indicates that cortical area is dependent on robusticity.

\section{Athletes and referents were then separated into two groups based on the partial regression} analysis. Although a continuum in SSIp and robusticity exists, those participants with negative residuals for both SSIp and robusticity with respect to body size (BW*Le) (bottom left quadrant of Figure 1D) were placed in a group labeled "weaker for size" (WS). The second group (top 
217 right quadrant of Figure 1D) was comprised of individuals with positive residuals for both SSIp

218 and robusticity with respect to body size (BW*Le) and labeled "stronger for size" (SS).

219 Anthropometric, muscle strength and bone trait variables from the 50\% tibial site were compared

220 between groups.

221

222 Differences between the two groups (WS and SS) were determined by unpaired t-tests (two-

223 tailed) with a significance value set at 0.05 . All statistical analyses (t-tests and regressions) were

224 performed using Graph Pad (GraphPad Prism version 6.00 for Windows, GraphPad Software,

225 San Diego, California, USA).

226

227 Results:

228

Robusticity and Bone Strength Relative to Body Size

230

231

At the $50 \%$ site, tibia robusticity (total cross-sectional area/tibia length) (Figure 1A) was

232 normally distributed with a range for females (.89-1.54) and for males (1.1-1.9). Robusticity increased modestly with body size $\left(\mathrm{BW}^{*} \mathrm{Le}\right)$, similar to previous studies (Females $\mathrm{R}^{2}=0.11$; Males $\mathrm{R}^{2}=0.36$ ) (Figure 1B). The Strength-Strain Index (SSIp) increased with body size $\left(\mathrm{BW}^{*} \mathrm{Le}\right)$ (Females: $\mathrm{R}^{2}=0.47$; Males: $\left.\mathrm{R}^{2}=0.55\right)$ (Figure $\left.1 \mathrm{C}\right)$. Robusticity correlated significantly with SSIp for both males and females after accounting for body size (BW*Le) (Females:

$237 \mathrm{R}^{2}=0.80$; Males: $\mathrm{R}^{2}=0.77$ ) (Figure 1D), indicating that SSIp was dependent on the robusticity 238 consistent with previous studies (Jepsen et al., 2011, 2013). The slopes of the female and male partial regression lines were significantly different. Bones with lower robusticity values had 
240 lower SSIp levels for body size. Bone strength (SSIp) was dependent on the robusticity of the

241 tibia (Figure 1D).

242

243 Anthropometrics, Muscle Function and Bone Functionality for WS vs SS groups

244

245 The tibia robusticity at the 50\% site in the WS group was $17-18 \%$ less than the SS group (Figure

$2462 \mathrm{~A}$ and $2 \mathrm{~B}$ ). The WS group had SSIp values that were $27.3 \%$ and $28.8 \%$ less in females and

247 males respectively compared to the SS group of individuals (Figure 2C). Cortical area values

248 were also significantly less, 19\% for both females and males (Figure 2D) in the WS groups. The

249 largest difference between the 2 groups was found in the polar moment of inertia $(\mathrm{J})$; females in

250 the WS group had a 31.4\% smaller J and males were 33.8\% smaller (Figure 2E). However,

251 cortical bone mineral density (cBMD) was similar for both groups (Figure 2F). Similar results

252 for the $25 \%$ tibia site were found but not reported here.

253

254 Although the bone traits that comprise bone strength were significantly different between the SS

255 and WS groups, there were minimal differences in the anthropometric and muscle function data

256 between groups (Table 1). Both groups had similar heights, yet the SS group had body weights

257 that were $8.5 \%$ greater in the females compared to the WS group. However, percent body fat

258 was not significantly different between groups but there was a large range within groups. The

259 female individual with the lowest body fat percentage was in the WS group and the male

260 individual with the lowest body fat percentage was in the SS group. Tibia lengths were not

261 significantly different between groups.

262 
263 Muscle areas measured at the 50\% tibia site were not different between groups for both females

264 and males (Table 1). The three muscle strength measurements were also similar between groups.

265 No differences were found in relative grip strength, leg extensor strength or relative power. The

266 WS group did not lack muscle strength suggesting that differences in bone strength were not due

267 to differences in muscular loading on the tibia.

268

269 Type of Sport for WS and SS groups

270

271 Table 2 indicates the percentage of individuals in the WS group. Similar numbers of female and

272 male runners (Track/CC) were in the WS group, 44\% and 43\% respectively. A lower percentage

273 of athletes from ball sports were "weaker for size" (WS group); 30\% and 33.3\% respectively for

274 females and males. The ball sport category included volleyball and soccer for females and

275 soccer and basketball for males. A large percentage of swimmers, $72 \%$ were in the WS group.

276 The number of referent individuals in the WS group was $75 \%$ for females and $82 \%$ for males.

277

278 Cortical Area in WS and SS groups

279

280

Adapting a bone to optimize bone strength may be limited by the cortical area of that bone. To

281

determine if any athletes or referent participants were "weaker for size" but fully adapted based

282

on cortical area, a partial regression analysis of cortical area and robusticity accounting for

283

$\mathrm{BW} *$ Le was done. If an individual had an expected or greater than expected cortical area for

their body size (positive residual values for Ct.Ar vs body size) they may also have relatively

weak bones for body size but the tibia reached the highest strength biologically possible based on 
286 their robusticity. Cortical area (Ct.Ar) was larger for individuals with larger body size (BW*Le)

287 (Females $\mathrm{R}^{2}=0.34$; Males $\mathrm{R}^{2}=0.48$ ) (Figure 3A). Cortical area (Ct.Ar) was also larger as the

288 robusticity of the bone increased (Females $\mathrm{R}^{2}=0.58$; Males $\mathrm{R}^{2}=0.76$ ) (Figure $\left.3 \mathrm{~B}\right)$. Robusticity

289 correlated significantly with Ct.Ar for both females and males after accounting for body size

$290\left(\mathrm{Bw}^{*} \mathrm{Le}\right)$, the slopes and intercepts of these partial regression lines were not different. Slender

291 bones (lower robusticity values) had less Ct.Ar than more robust tibias (Females $\mathrm{R}^{2}=0.56$; Males

$292 \mathrm{R}^{2}=0.63$ ) (Figure 3C). Cortical area adjusted for body size and regressed against robusticity was

293 similar to the relationship reported in previous studies (Jepsen, 2011; Jepsen et al., 2011).

295 Six athletes in the "weaker for size" group were found to have positive residual values from the 296 Ct.Ar vs BW*Le regression (Figure 3A). These athletes are found in the top left quadrant of 297 Figure 3C, indicating that they had negative residuals for robusticity but a positive residual value 298 for Ct.Ar after accounting for BW*Le. Slender bones had smaller cortical areas, but some 299 athletes adequately adapted their tibia yet did not have the same functionality (bone 300 strength/body size) as athletes with more robust bones.

301

302

Discussion

The current results for Division II collegiate athletes and referents were consistent with other 304 studies of young healthy adults (Jepsen, 2011; Jepsen et al., 2013) indicating that a range of bone strength values based on robusticity occurs in athletes. Tibia robusticity varied $\sim 2$ fold for both females and males in the current study similar to the range found in healthy young populations (Jepsen et al., 2011). Bone strength (SSIp) values ranged 83\% (range/average) for females and $308133 \%$ in males. The athletes did not all develop similar bone strength relative to body size and 
309 some athletes developed bones that were "weaker for size" (WS) and other athletes developed

310 bones that were "stronger for size" (SS). A significant difference in average SSIp of

311 approximately $27 \%$ was found between the tibias that were slender relative to BW*Le (WS

312 group) compared to robust tibias (SS group). The "weaker for size" (WS) individuals also had

313 significantly lower cortical area and polar moment of inertia (J) values compared to the SS group

314 with no difference in cortical bone mineral density (cBMD). There were no differences in height

315 or body fat percentage between groups however the athletes in the female SS group were

316 heavier. In addition, no differences in muscle strength were found. The between groups

317 variation in strength values is normal in healthy populations (Jepsen et al., 2013). However,

318 athletes perform loading activities outside the norm and thus athletes with low robusticity in their

319 tibia may have weaker bone strength and may be susceptible to repetitive loading injuries.

Robusticity and Bone Strength

Athletes as a group typically have greater bone strength compared to control groups (Heinonen et al., 2002; Kontulainen et al., 2003; Greene et al., 2012; Korhonen et al., 2012; Warden \& Roosa, 2014). Athletes presumably undergo bone functional adaptation to be able to withstand the loading demands of their sport without injury (Ruff, Holt \& Trinkaus, 2006; Hughes et al., 2016). Bones functionally adapt to their loading as described by Wolff's Law (Wolff, 1892). The proposed stimulus for this adaptation is mechanical strain as described by the mechanostat theory introduced by Harold Frost (Frost, 2003). However, bone strength in the current study did vary based on bone robusticity (Jepsen et al., 2011, 2013; Jepsen, Bigelow \& Schlecht, 2015) and the robusticity range in the athletes in the current study was similar to healthy populations 
331 (1.1 fold for females and males). The skeletal system is functional over a range of bone

332 strengths in healthy populations and although slender bones tend to be less strong compared to

333 robust bones (Jepsen et al., 2013) they are strong enough to withstand daily loads. A previous

334 study reported a 2-fold difference in bone stiffness was not pathological but a natural variant that

335 is expected in populations (Jepsen et al., 2013). However, slender bones have been associated

336 with increased risk of stress fracture (Beck et al., 2000; Popp et al., 2009; Schnackenburg et al.,

337 2011; Jepsen et al., 2013). Male military recruits presenting with a stress fracture had 5.3\%

338 lower robusticity and 11\% lower tibial stiffness (Jepsen et al., 2013) compared to non-fracture

339 recruits. In the current study, the "weaker for size" group had 27-29\% lower SSIp values and

340 approximately $17 \%$ lower robusticity values compared to the SS group. Decreased strength for

341 size may not be a problem for activities of daily living in healthy populations but may become a

342 problem under extreme loading conditions such as those experienced by athletes during training

343 and competition.

344 Bone structure and architecture adapts as a response to mechanical loading with a goal to

345 maintain optimum strain levels during the performance of activities. Therefore, if activity levels

346 increase, the architecture of the bone may change to maintain the strain levels (Rubin \& Lanyon,

347 1984; Forwood, 2008; Hughes et al., 2016). However, if biological processes are unable to adapt

348 bone traits such as cortical area, moment of inertia, and tissue mineral density to establish the

349 same level of functionality between robust and more slender bones then strength will be affected.

350 Athletes even after optimal training for their sport may have weaker bones relative to body size

351 based on robusticity. Robusticity is established early in life by 2 years of age (Pandey et al.,

352 2009). The variation in robusticity in healthy populations is in part based on genetics and as well

353 as the activity levels of individuals. Skeletal robusticity has been used as an outcome measure to 
354 study mobility of groups in anthropological studies, the greater amounts of terrestrial locomotion

355 have been linked to greater lower limb robusticity (Carlson \& Marchi, 2014). Adolescence is a

356 time period that elicits a bone adaptive response (Kannus et al., 1995; Forwood, 2008), athletes

357 who start their sport during or prior to puberty have long term effects on bone structure (Warden

358 \& Roosa, 2014; Jackowski et al., 2014). Therefore, collegiate level athletes who are assumed to

359 have started their athletic careers prior or during puberty would have the best chance to optimize

360 their robusticity and bone strength. However, the coefficient of variation for robusticity in the

361 current study was $15 \%$, which was very similar to variations found in studies of healthy

362 populations (Pandey et al., 2009). Even in trained athletes, robusticity may affect their ability to

363 develop adequate bone strength for the demands of sport.

365 Cortical Area and Bone Strength relative to Body Size

366 Injury occurs when the loading on a tissue exceeds the strength of that tissue. For bone, if the

367 loading from daily activities and/or sport and exercise exceed the bone strength then stress

368 fracture may result. To avoid injury, athletes must either increase the strength of their bones or

369 decrease the loading on their bones. Athletes ideally want to maximize bone strength while

370 minimizing bone mass. Slender bones result in greater tissue strains potentially damaging the

371 cortical matrix and increasing the probability of fracturing (Burr et al., 1998) and have been

372 associated with stress fracture in military recruits (Jepsen et al., 2013). However, slender

373 phenotypes are not indicative of a bone that is "poorly adapted". An individual can have lower

374 tibia strength per body size and have less robust (slender) tibias for body size, and thus have

375 reduced functionality, BUT have a well-adapted structure IF their cortical area is expected or 
376 greater than expected for body size (Jepsen et al., 2013). There may be a selective advantage in

377 sport for a bone with minimal mass and maximal strength. While robust bones tend to be

378 stronger they are also larger. Larger bones (increased mass) are metabolically expensive which

379 may be a detriment for athletes in certain sports. The regression of robusticity and Ct.Ar after

380 adjusting for body size (BW* Le) indicated that athletes and referents with less robust tibias had

381 lower Ct.Ar in general (Figure 3B, Figure 3C). However, analysis of the data found some

382 athletes with less robust tibias and greater than expected cortical area, these athletes had tibias

383 that had impaired functionality but were optimally adapted based on their robusticity. These

384 athletes had "weaker for size" bones but had adequate cortical area and therefore may have

385 reached the limits in their ability to increase their bones' strength. These athletes may need to

386 adjust their loading to reduce injury potential. A large percentage of swimmers were in the WS

387 group, and due to the lack of gravity during their sport this may be an advantage. Yet, the

388 athletes in the "weaker for size" group that are involved in impact sports (soccer, volleyball and

389 basketball) may have a greater risk for injury.

391 Tibia length, height, and percent body fat were all similar between the WS and SS groups for

392 both females and males. There was also no difference in muscle function between the athletes

393 that were "weaker for size" and those that were "stronger for size". The relative grip strength

394 measured by hand dynamometer which is an indicator of total body strength was similar between

395 groups. The relative leg extensor strength and lower body relative power were similar between

396 groups. In addition, the muscle area measured at the $50 \%$ tibial site by pQCT was similar

397 between groups. Athletes with similar anthropometry (body size) and body composition may

398 have very different bone strength and adaptation capacities based on the robusticity of their 
399 bones.

400

401

In-vivo Bone Strength Measures

402 Although a direct measurement of bone strength is ideal, it is not feasible in studies using human 403 subjects. Bone strength is determined by the size and shape (architecture) of a bone as well as 404 the material properties of the bone (Turner \& Burr, 1993; Van der Meulen, Jepsen \& Mikić, 405 2001). Bone strength analysis via pQCT allows an analysis of bone strength, including both the 406 structural and material properties. The parameter strength- strain index (SSIp), was developed to 407 approximate bone strength in-vivo (Ferretti et al., 2001) and has been shown to be a good 408 estimate of mechanical strength ex-vivo (Augat et al., 1998). Studies that measured strength via 409 SSIp during development indicate a minimal change in cBMD but a large variation in structural 410 variables of 300-400\% (Schoenau et al., 2001). Males grow stronger bones due to the exclusive 411 addition of bone mass on the periosteal surface where the effect on mechanical strength is much 412 greater than adding bone mass to the endocortical surface. Women tend to add bone to the endocortical surface for future calcium needs during pregnancy and lactation (Kovacs \&

414 Kronenberg, 1997). In the current study, we found no differences in cBMD between the "weaker 415 for size" and "stronger for size" groups; the main differences in bone strength stem from 416 differences in bone cortical area and polar moment of inertia. Differences in cortical area are 417 dependent on the robusticity of the bone that is not apparent by looking at muscle strength or 418 body size of an athlete. 
421 The limitations of our study include the cross-sectional nature of the data. We also did not track

422 injury in our population due to the small participant number and the activity level of our

423 reference group was not directly measured. In addition, other factors not measured in the current

424 study may affect bone strength values in addition to body size and robusticity including systemic

425 factors, nutrition and specific training load modalities. There were also advantages, as both our

426 athlete and reference samples were ethnically diverse and previous studies have utilized more

427 homogenous groups (Jepsen et al., 2011, 2013). Most of the athletes and referents in the current

428 study were non-white (68.5\% - 90\% dependent on group). Furthermore, previous studies suggest

429 that a portion of the variation in robusticity may be due to other aspects not represented by body

430 size $\left(\mathrm{BW}^{*} \mathrm{Le}\right)$ including the type of activity, intensity, duration and age of onset of sport. Our

431 population of collegiate athletes probably started their sport during adolescence (Frisch et al.,

4321985 ) and as a result was able to optimize their robusticity and functional adaptation. Yet the

433 range of robusticity values of the athletes was similar to those found in healthy populations.

Conclusions:

Division II collegiate athletes had a variation in tibial robusticity and bone strength (measured by

438 SSIp) similar to those previously reported in healthy populations (Jepsen et al., 2011, 2013;

439 Jepsen, Bigelow \& Schlecht, 2015). Athletes may tend to have stronger bones when viewed as a 440 group but when analyzed as individuals bone strength was found to be dependent on robusticity. 
441 The athletes with slender bones were from all sports including track and field and ball sports but

442 the majority were swimmers. Slender bones were constructed with less bone tissue and have less

443 strength (SSIp) suggesting these bones were at a functional disadvantage compared to bones with

444 higher robusticity (Jepsen et al., 2011). Slender bones may therefore be at a higher risk for

445 fracture under extreme loading events but also yield benefits to some athletes (swimmers) due to

446 their lower bone mass. Athletes with slender bones may have normal bone adaptation to loading

447 based on their cortical area but still have bones that are functionally impaired. To avoid injury,

448 robusticity of an athlete and the effect on bone strength and adaptation needs to be considered as

449 training programs are designed. Finally, the athletes with slender bones were not easily

450 identified by anthropometric or muscle strength variables.

451

452 Acknowledgments

453

454 We would like to thank the California State University East Bay - Center for Student Research, 455 Kinesiology Research Group (KRG) and the Department of Athletics

References

458

459

460
Augat P., lida H., Jiang Y., Diao E., Genant HK. 1998. Distal radius fractures: mechanisms of injury and strength prediction by bone mineral assessment. Journal of Orthopaedic Research: Official Publication of the Orthopaedic Research Society 16:629-635. DOI: 10.1002/jor.1100160517. 
461 Beck TJ., Ruff CB., Shaffer RA., Betsinger K., Trone DW., Brodine SK. 2000. Stress fracture in military

462 recruits: gender differences in muscle and bone susceptibility factors. Bone 27:437-444.

463 Burr DB., Turner CH., Naick P., Forwood MR., Ambrosius W., Hasan MS., Pidaparti R. 1998. Does

464

465 microdamage accumulation affect the mechanical properties of bone? Journal of Biomechanics

466 31:337-345.

Carlson KJ., Marchi D. 2014. Reconstructing Mobility: Environmental, Behavioral, and Morphological Determinants. New York, NY: Springer.

Cointry G., Ferretti JL., Reina PS., Nocciolono LM., Rittweger J., Capozza RF. 2014. The pQCT “Bone Strength Indices"(BSIs, SSI). Relative mechanical impact and diagnostic value of the indicators of bone tissue and design quality employed in their calculation in healthy men and pre-and postmenopausal women. Journal of Musculoskeletal and Neuronal Interactions 14:29-40.

Crossley K., Bennell KL., Wrigley T., Oakes BW. 1999. Ground reaction forces, bone characteristics, and tibial stress fracture in male runners. Medicine and Science in Sports and Exercise 31:1088-1093.

Ferretti JL., Cointry GR., Capozza RF., Capiglioni R., Chiappe MA. 2001. Analysis of biomechanical effects on bone and on the muscle-bone interactions in small animal models. J Musculoskelet Neuronal Interact 1:263-274.

Forwood MR. 2008. Physical activity and bone development during childhood: insights from animal models. Journal of Applied Physiology 105:334-341. DOI: 10.1152/japplphysiol.00040.2008.

Fredericson M., Jennings F., Beaulieu C., Matheson GO. 2006. Stress fractures in athletes. Topics in Magnetic Resonance Imaging 17:309-325.

Frisch RE., Wyshak G., Albright NL., Albright TE., Schiff I., Jones KP., Witschi J., Shiang E., Koff E., Marguglio M. 1985. Lower prevalence of breast cancer and cancers of the reproductive system among former college athletes compared to non-athletes. British Journal of Cancer 52:885. 
484 Frost HM. 2003. Bone's mechanostat: A 2003 update. The Anatomical Record 275A:1081-1101. DOI:

485

486

487

488

489

490

491

492

493

494

495

496

497

498

499

500

501

502

503

504

505

506

10.1002/ar.a.10119.

Greene DA., Naughton GA., Bradshaw E., Moresi M., Ducher G. 2012. Mechanical loading with or without weight-bearing activity: influence on bone strength index in elite female adolescent athletes engaged in water polo, gymnastics, and track-and-field. Journal of Bone and Mineral Metabolism 30:580-587. DOI: 10.1007/s00774-012-0360-6.

Haapasalo H., Kontulainen S., Sievänen H., Kannus P., Järvinen M., Vuori I. 2000. Exercise-induced bone gain is due to enlargement in bone size without a change in volumetric bone density: a peripheral quantitative computed tomography study of the upper arms of male tennis players. Bone 27:351-357.

Heaney RP., Abrams S., Dawson-Hughes B., Looker A., Marcus R., Matkovic V., Weaver C. 2000. Peak bone mass. Osteoporosis international: a journal established as result of cooperation between the European Foundation for Osteoporosis and the National Osteoporosis Foundation of the USA 11:985-1009. DOI: 10.1007/s001980070020.

Heinonen A., Sievänen H., Kannus P., Oja P., Vuori I. 2002. Site-Specific Skeletal Response to Long-Term Weight Training Seems to be Attributable to Principal Loading Modality: A pQCT Study of Female Weightlifters. Calcified Tissue International 70:469-474. DOI: 10.1007/s00223-001-1019-9.

Hughes JM., Popp KL., Yanovich R., Bouxsein ML., Matheny RW. 2016. The role of adaptive bone formation in the etiology of stress fracture. Experimental Biology and Medicine. DOI: $10.1177 / 1535370216661646$.

Jackowski SA., Kontulainen SA., Cooper DML., Lanovaz JL., Beck TJ., Baxter-Jones ADG. 2014. Adolescent Physical Activity and Bone Strength at the Proximal Femurin Adulthood: Medicine \& Science in Sports \& Exercise 46:736-744. DOI: 10.1249/MSS.0000000000000154. 
507 Jepsen KJ. 2011. Functional interactions among morphologic and tissue quality traits define bone

508

509

510

511

512

513

514

515

516

517

518

519

520

521

522

523

524

525

526

527

528

529

530 quality. Clinical Orthopaedics and Related Research 469:2150-2159. DOI: 10.1007/s11999-0101706-9.

Jepsen KJ., Bigelow EMR., Schlecht SH. 2015. Women Build Long Bones With Less Cortical Mass Relative to Body Size and Bone Size Compared With Men. Clinical Orthopaedics and Related Research ${ }^{\circledR}$. DOI: 10.1007/s11999-015-4184-2.

Jepsen KJ., Centi A., Duarte GF., Galloway K., Goldman H., Hampson N., Lappe JM., Cullen DM., Greeves J., Izard R., Nindl BC., Kraemer WJ., Negus CH., Evans RK. 2011. Biological constraints that limit compensation of a common skeletal trait variant lead to inequivalence of tibial function among healthy young adults. Journal of Bone and Mineral Research 26:2872-2885. DOI: 10.1002/jbmr.497.

Jepsen KJ., Evans R., Negus CH., Gagnier JJ., Centi A., Erlich T., Hadid A., Yanovich R., Moran DS. 2013. Variation in tibial functionality and fracture susceptibility among healthy, young adults arises from the acquisition of biologically distinct sets of traits. Journal of Bone and Mineral Research: The Official Journal of the American Society for Bone and Mineral Research 28:1290-1300. DOI: 10.1002/jbmr.1879.

Jones BH. 2002. Prevention of Lower Extremity Stress Fractures in Athletes and Soldiers: A Systematic Review. Epidemiologic Reviews 24:228-247. DOI: 10.1093/epirev/mxf011.

Kannus P., Haapasalo H., Sankelo M., Sievänen H., Pasanen M., Heinonen A., Oja P., Vuori I. 1995. Effect of starting age of physical activity on bone mass in the dominant arm of tennis and squash players. Annals of Internal Medicine 123:27-31.

Kohrt WM., Bloomfield SA., Little KD., Nelson ME., Yingling VR. 2004. Physical Activity and Bone Health: Medicine \& Science in Sports \& Exercise 36:1985-1996. DOI: 10.1249/01.MSS.0000142662.21767.58. 
531 Kontulainen S., Sievänen H., Kannus P., Pasanen M., Vuori I. 2003. Effect of Long-Term Impact-Loading

532 on Mass, Size, and Estimated Strength of Humerus and Radius of Female Racquet-Sports Players:

533 A Peripheral Quantitative Computed Tomography Study Between Young and Old Starters and 534 Controls. Journal of Bone and Mineral Research 18:352-359. DOI: 10.1359/jbmr.2003.18.2.352.

535 Korhonen MT., Heinonen A., Siekkinen J., Isolehto J., AléN M., Kiviranta I., Suominen H. 2012. Bone

536 Density, Structure and Strength, and Their Determinants in Aging Sprint Athletes: Medicine \&

537 Science in Sports \& Exercise 44:2340-2349. DOI: 10.1249/MSS.0b013e318267c954.

538 Kovacs CS., Kronenberg HM. 1997. Maternal-fetal calcium and bone metabolism during pregnancy, 539 puerperium, and lactation. Endocrine Reviews 18:832-872. DOI: 10.1210/edrv.18.6.0319.

540 Pandey N., Bhola S., Goldstone A., Chen F., Chrzanowski J., Terranova CJ., Ghillani R., Jepsen KJ. 2009.

$541 \quad$ Interindividual Variation in Functionally Adapted Trait Sets Is Established During Postnatal

542 Growth and Predictable Based on Bone Robustness. Journal of Bone and Mineral Research

543 24:1969-1980. DOI: 10.1359/jbmr.090525.

544 Popp KL., Hughes JM., Smock AJ., Novotny SA., Stovitz SD., Koehler SM., Petit MA. 2009. Bone geometry, 545 strength, and muscle size in runners with a history of stress fracture. Medicine and Science in $546 \quad$ Sports and Exercise 41:2145-2150. DOI: 10.1249/MSS.0b013e3181a9e772.

547 Rubin CT., Lanyon LE. 1984. Dynamic strain similarity in vertebrates; an alternative to allometric limb $548 \quad$ bone scaling. Journal of Theoretical Biology 107:321-327.

549 Ruff C., Holt B., Trinkaus E. 2006. Who's afraid of the big bad Wolff?: "Wolff's law" and bone functional 550 adaptation. American Journal of Physical Anthropology 129:484-498. DOI: 10.1002/ajpa.20371.

551 Sayers SP., Harackiewicz DV., Harman EA., Frykman PN., Rosenstein MT. 1999. Cross-validation of three 552 jump power equations. Medicine and Science in Sports and Exercise 31:572-577. 
553 Schlecht SH., Jepsen KJ. 2013. Functional integration of skeletal traits: an intraskeletal assessment of 554 bone size, mineralization, and volume covariance. Bone 56:127-138. DOI:

555 10.1016/j.bone.2013.05.012.

556

557

558

559

560

561

562

563

564

565

566

567

568

569

570

571

572

573

Schnackenburg KE., Macdonald HM., Ferber R., Wiley JP., Boyd SK. 2011. Bone quality and muscle strength in female athletes with lower limb stress fractures. Medicine and Science in Sports and Exercise 43:2110-2119. DOI: 10.1249/MSS.0b013e31821f8634.

Schoenau E., Neu CM., Rauch F., Manz F. 2001. The development of bone strength at the proximal radius during childhood and adolescence. The Journal of Clinical Endocrinology \& Metabolism $86: 613-618$.

Taes Y., Lapauw B., Griet V., De Bacquer D., Goemaere S., Zmierczak H., Kaufman J-M. 2010. Prevalent fractures are related to cortical bone geometry in young healthy men at age of peak bone mass. Journal of Bone and Mineral Research 25:1433-1440. DOI: 10.1002/jbmr.17.

Turner CH., Burr DB. 1993. Basic biomechanical measurements of bone: a tutorial. Bone 14:595-608.

Van der Meulen MCH., Jepsen KJ., Mikić B. 2001. Understanding bone strength: size isn't everything. Bone 29:101-104.

Warden SJ., Roosa SMM. 2014. Physical activity completed when young has residual bone benefits at 94 years of age: a within-subject controlled case study. Journal of musculoskeletal \& neuronal interactions 14:239.

Wolff J. 1892. Das Gesetz der Transformation der Knochen. Berlin: A. Hirchwild. 
574 Figure Captions

575

576 Figure 1: (A) Tibial robusticity (Tt.Ar/Le) measured at the 50\% site varied widely among

577 females (range .89-1.54) and males (range 1.1-1.9). (B) Robusticity increased modestly with

$578 \mathrm{BW}^{*}$ Le for females $\left(\mathrm{R}^{2}=0.11\right)$ and males $\left(\mathrm{R}^{2}=0.36\right)$. (C) SSIp increased with $\mathrm{BW}^{*}$ Le for

579 females $\left(R^{2}=0.47\right)$ and males $\left(R^{2}=0.55\right)$. (D) Robusticity correlated significantly with SSIp for

580 both males and females after accounting for loading ( $\mathrm{BW}^{*} \mathrm{Le}$ ) (females: $\mathrm{R}^{2}=0.80$; males:

$\left.581 \mathrm{R}^{2}=0.77\right)$ * indicates significant regression $\mathrm{p}<0.05$

582 Figure 2: Comparison of the "weaker for size" (F-WS, M-WS) groups and "stronger for size" (F583 SS, M-SS) groups. (A) Robusticity for the WS group was 17\% less in females compared to the 584 SS group and (B) $18 \%$ less in males. (C) The WS groups for both females and males were 585 significantly weaker than the SS groups $(p=0.0001)$. (D) The cortical area for both females and 586 males in the WS groups were significantly smaller than the SS groups $(p=0.0003)$. (E) The 587 largest difference between WS and SS groups was in the polar moment of inertia $(J)(p=0.0003)$. 588 (F) No differences were found between groups for volumetric bone mineral density (cBMD).

589 Figure 3: (A) Cortical area (Ct.Ar) increased as the magnitude of loading (BW*Le) for both 590 females and males. (B) Cortical area (Ct.Ar) was greater as the robusticity of the bone increased 591 for both females and males. (C) Robusticity correlated significantly with Ct.Ar for both females 592 and males after accounting for loading $\left(\mathrm{Bw}^{*} \mathrm{Le}\right)$. The slopes and intercepts of these regression 593 lines were not different.

Table 1: Comparison of anthropometric and muscle strength and function variables between the 596 SS group ("stronger for size") and the WS group ("weaker for size") in both females and males.

598 Table 2: Percentage of participants in the WS "weaker for size” group. 


\section{Table $\mathbf{1}$ (on next page)}

Comparison of anthropometric and muscle strength and function variables between the SS group ("stronger for size") and the WS group ("weaker for size") in both females and males.

Comparison of anthropometric and muscle strength and function variables between the SS group ("stronger for size") and the WS group ("weaker for size") in both females and males. 
1 Table 1: Comparison of anthropometric and muscle strength and function variables between the 2 SS group ("stronger for size") and the WS group ("weaker for size") in both Females and Males.

3

\begin{tabular}{ccccc}
\hline & \multicolumn{2}{c}{ Females } & \multicolumn{2}{c}{ Males } \\
\hline Anthropometrics & F-SS & F-WS & M-SS & M-WS \\
\hline Body Weight $(\mathrm{kg})$ & $65.0(8.9)$ & $59.4(8.9)^{*}$ & $75.7(9.0)$ & $73.4(10.8)$ \\
Height $(\mathrm{m})$ & $1.68(0.08)$ & $1.63(0.09)$ & $1.78(0.10)$ & $1.75(0.05)$ \\
Body Fat \% & $20.4(6.1)$ & $21.0(4.8)$ & $9.5(3.7)$ & $13.5(6.8)$ \\
Tibial Le (mm) & $356.1(27.6)$ & $358.5(32.1)$ & $386.3(29.5)$ & $382.9(31.0)$ \\
\hline Muscle & & & & \\
\hline Muscle Area (mm $\left.{ }^{2}\right)$ & $4399(649)$ & $4492(682)$ & $5820(710)$ & $5191(898)$ \\
Grip Strength (N/kg) & $6.0(1.0)$ & $6.0(1.1)$ & $8.1(1.2)$ & $7.4(1.5)$ \\
1 RM Leg Press/ BW & $2.6(0.7)$ & $2.3(0.5)$ & $3.1(1.0)$ & $3.1(0.9)$ \\
Relative Power (W/kg) & $50.8(8.4)$ & $52.4(7.4)$ & $60.8(9.6)$ & $62.3(10.8)$ \\
\hline
\end{tabular}
Values are presented as mean + SD., * indicates difference from SS group $p<0.05$, 


\section{Table 2 (on next page)}

Participants in the weaker for size group.

Percentage of participants in the WS "weaker for size" group. 
1 Table 2: Percentage of individuals in the WS "weaker for size" group in the following categories;

2 Track/CC, Ball Sports, Swimming, Referent for both Females and Males.

\begin{tabular}{ccc}
\hline & Females & Males \\
\cline { 2 - 3 } Track- Cross Country & $44 \%$ & $43 \%$ \\
Ball Sports* & $30 \%$ & $33.3 \%$ \\
Swimming & $72 \%$ & N/A \\
Referent & $75 \%$ & $82 \%$ \\
\hline
\end{tabular}

3

* Included volleyball and soccer for females and soccer and basketball for males

4 
Figure 1

Robusticity and bone strength

(A) Tibial robusticity (Tt.Ar/Le) measured at the $50 \%$ site varied widely among females (range .89-1.54) and males (range 1.1-1.9). (B) Robusticity increased modestly with BW*Le for females $\left(R^{2}=0.11\right)$ and males $\left(R^{2}=0.36\right)$. (C) SSIp increased with BW*Le for females $\left(R^{2}=0.47\right)$ and males $\left(R^{2}=0.55\right)$. (D) Robusticity correlated significantly with SSIp for both males and females after accounting for loading (BW*Le) (females: $\mathrm{R}^{2}=0.80$; males: $\mathrm{R}^{2}=0.77$ ). ${ }^{*}$ indicates significant regression $p<0.05$

A.

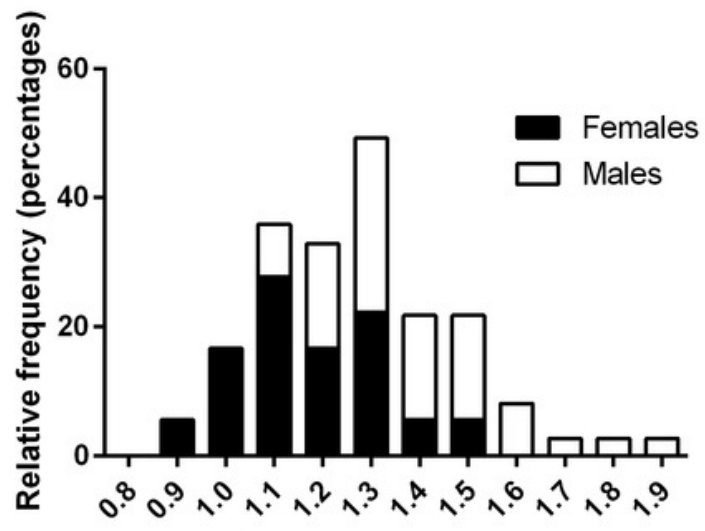

Robusticity (Tt.Ar/Le)

C.

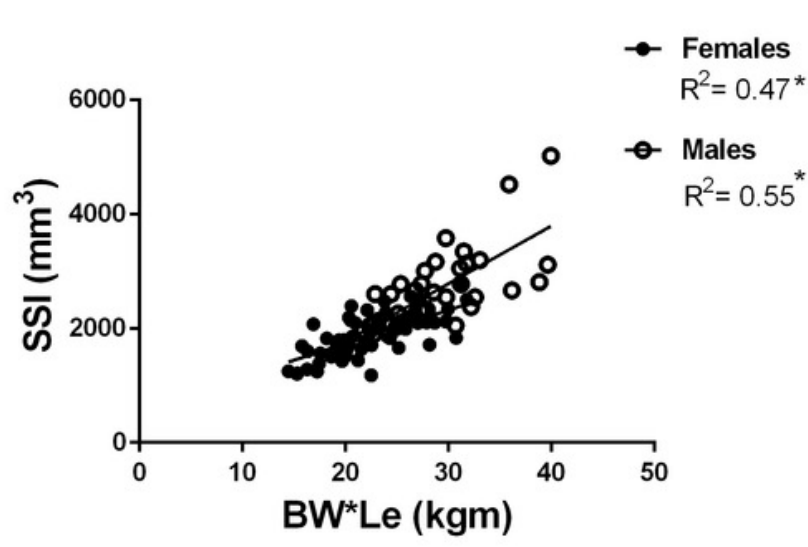

B.

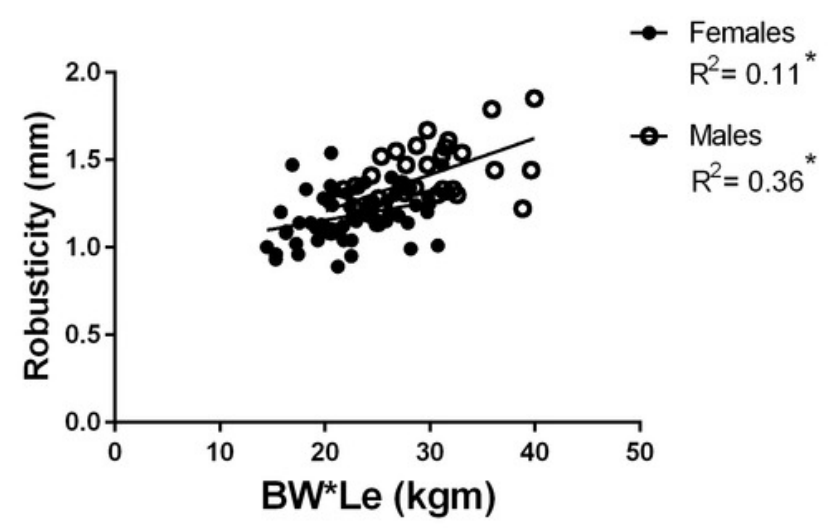

D.

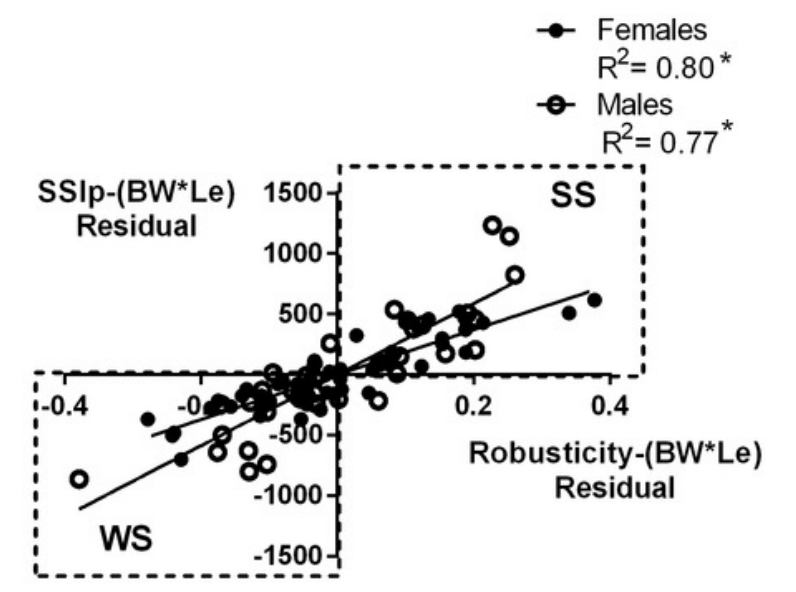




\section{Figure 2}

Comparison of the "weaker for size" (F-WS, M-WS) groups and "stronger for size" (F-SS, M-SS) groups.

Comparison of the "weaker for size" (F-WS, M-WS) groups and "stronger for size" (F-SS, MSS) groups. (A) Robusticity for the WS group was $17 \%$ less in females compared to the SS group and (B) $18 \%$ less in males. (C) The WS groups for both females and males were significantly weaker than the SS groups $(p=0.0001)$. (D) The cortical area for both females and males in the WS groups were significantly smaller than the SS groups $(p=0.0003)$. ( $E)$ The largest difference between WS and SS groups was in the polar moment of inertia (J) $(p=0.0003)$. ( $F)$ No differences were found between groups for volumetric bone mineral density (CBMD). 
A.

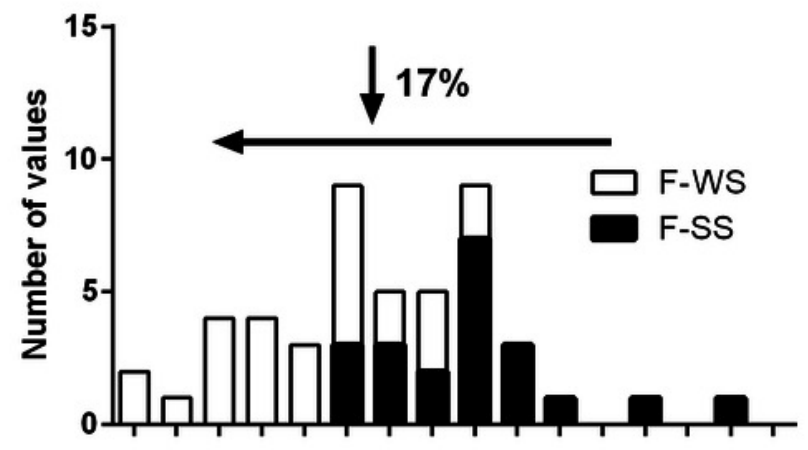

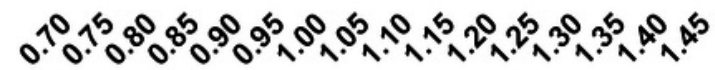

C.

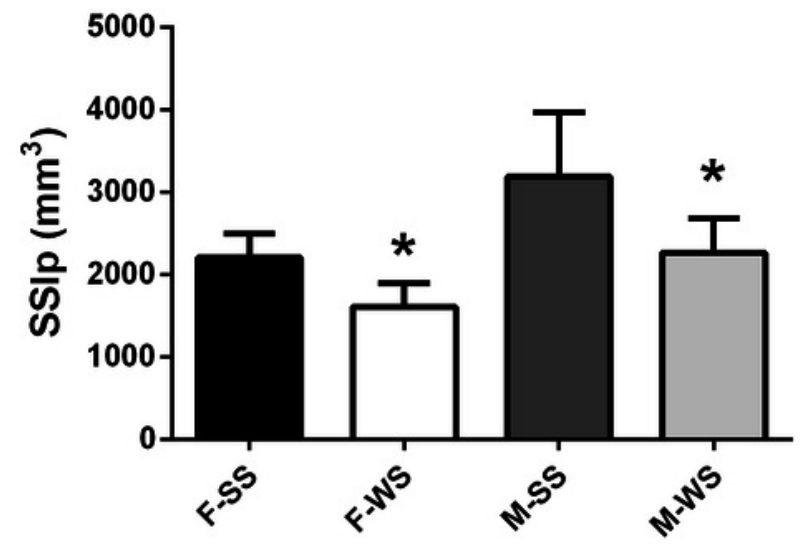

E.

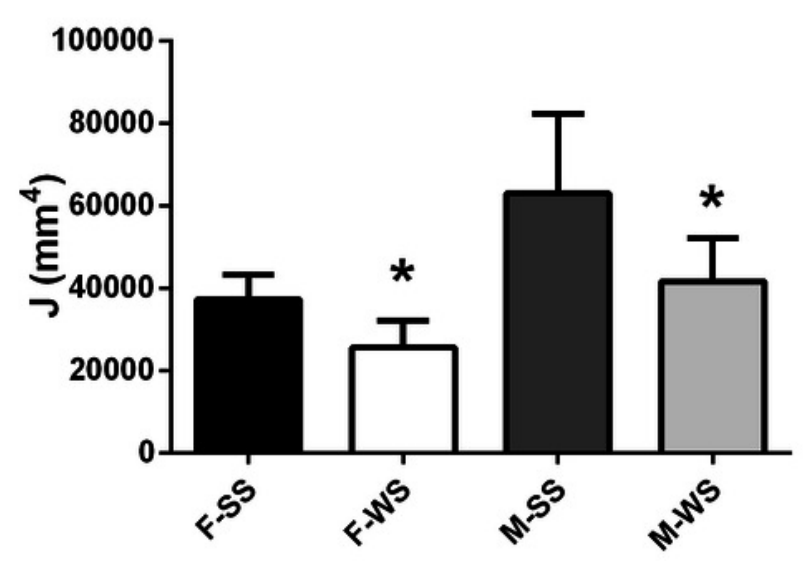

B.

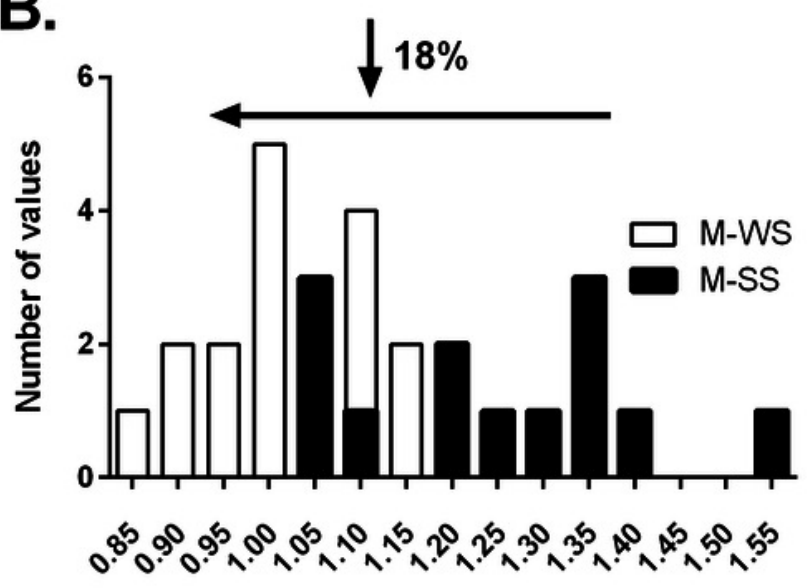

D.

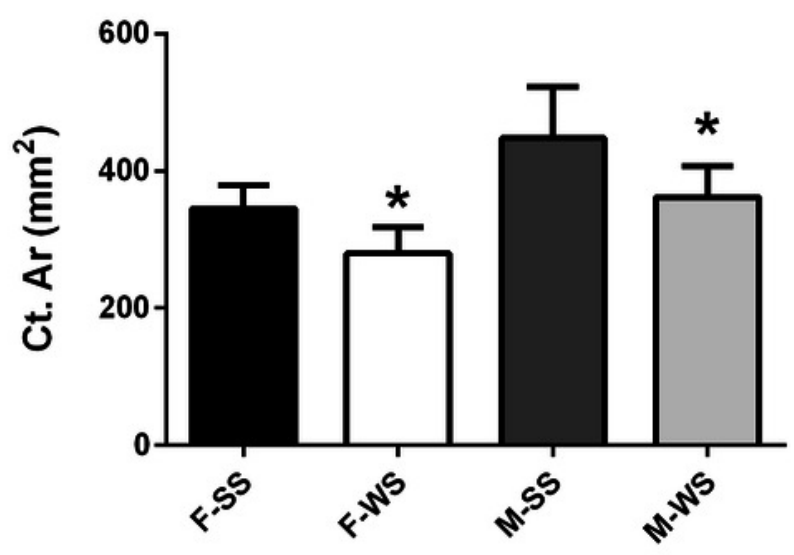

F.

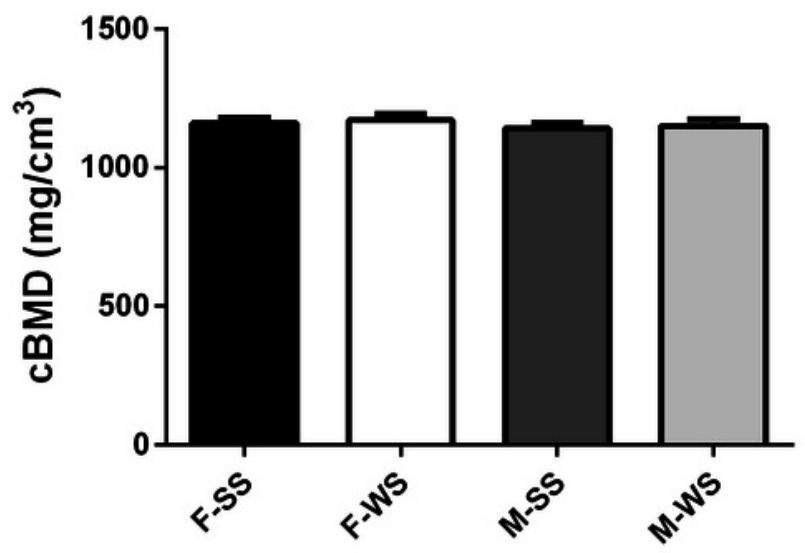




\section{Figure 3}

\section{Cortical Area and Robusticity}

(A) Cortical area (Ct.Ar) increased as the magnitude of loading (BW*Le) for both females and males. (B) Cortical area (Ct.Ar) was greater as the robusticity of the bone increased for both females and males. (C) Robusticity correlated significantly with Ct.Ar for both females and males after accounting for loading (Bw*Le). The slopes and intercepts of these regression lines were not different. 
A.

B.
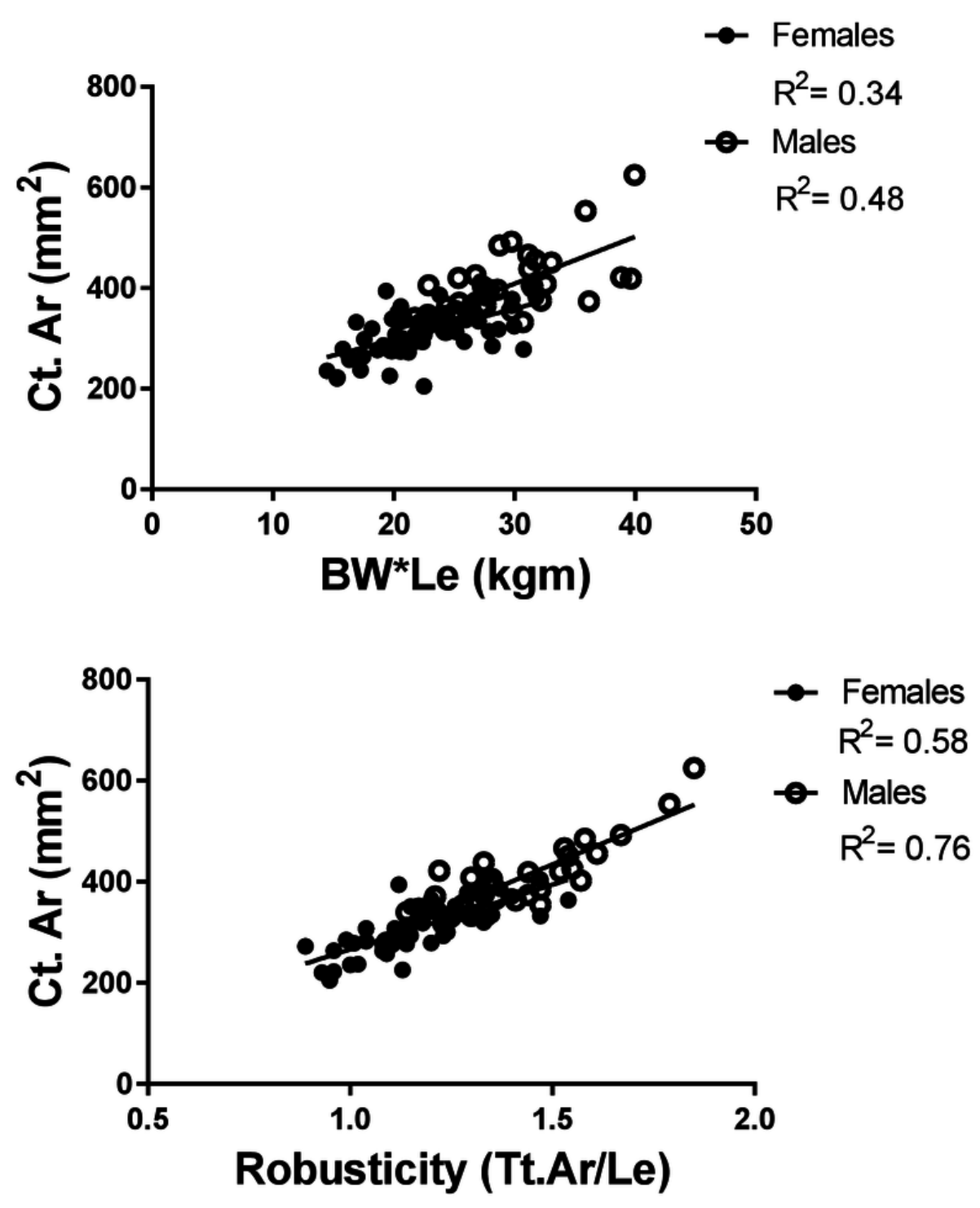

c.

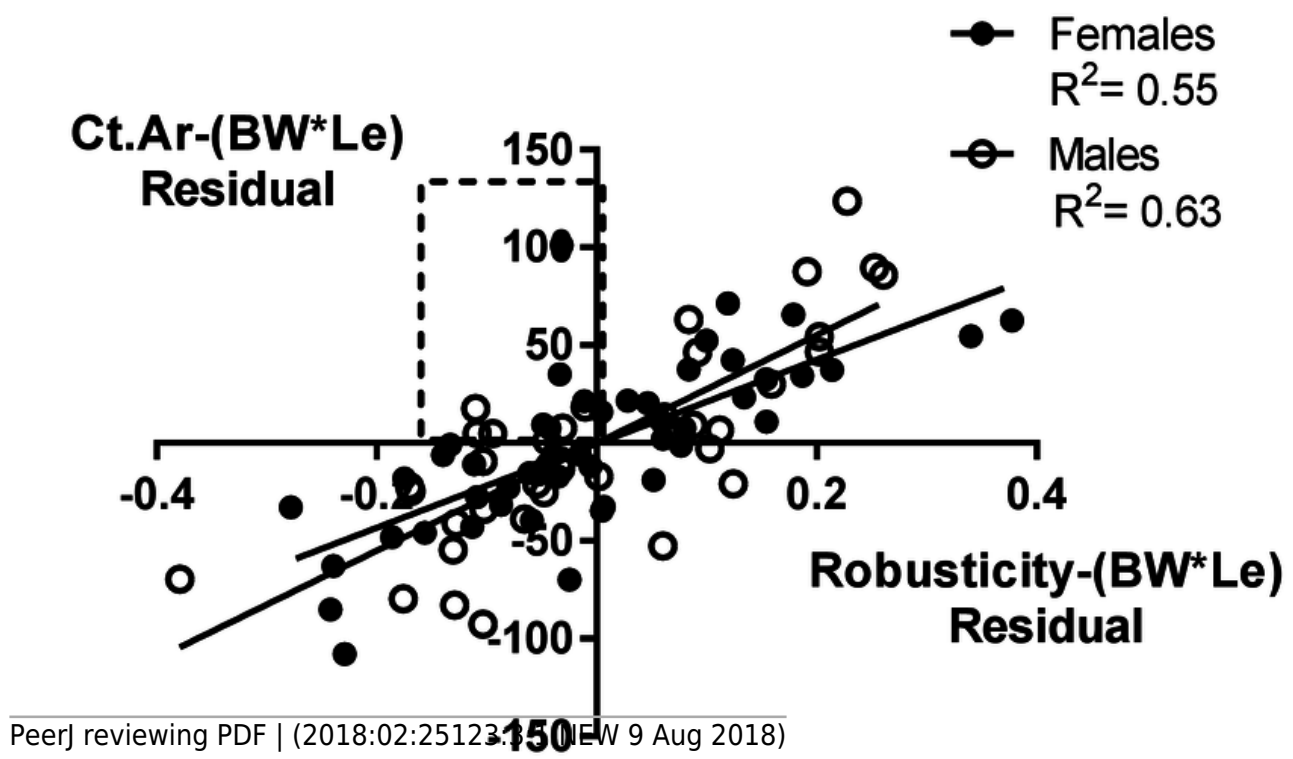

